\title{
A case-control study of selenium in nails and prostate cancer risk in British men
}

\author{
NE Allen*,1, JS Morris'², RA Ngwenyama ${ }^{2}$ and TJ Key' \\ 'Cancer Research UK Epidemiology Unit, University of Oxford, Gibson Building, Radcliffe Infirmary, Oxford OX2 6HE, UK; ${ }^{2}$ University of Missouri- \\ Columbia, Research Reactor Center, Columbia, MO 65211, USA
}

In view of the experimental evidence suggesting that the micronutrient selenium reduces prostate cancer risk, we investigated the association between the selenium level in fingernails, a measure of long-term selenium intake, and prostate cancer risk in a case-control study among 656 British men, conducted in 1989-1992. Nail clippings were taken at the time of recruitment and selenium concentration, measured using neutron activation techniques, was successfully assayed for 300 case-control pairs and varied six-fold among the controls (0.59 p.p.m.; interquartile range, $0.50-0.7$ l p.p.m.). Nail selenium concentration was not significantly associated with prostate cancer risk: men in the highest quartile of nail selenium had a slightly increased risk compared with men in the lowest quartile (OR 1.24, $95 \mathrm{Cl}, 0.73-2.10$ ); for advanced prostate cancer, men in the highest quartile had a slightly reduced risk compared with men in the lowest quartile (OR $0.78,95 \% \mathrm{Cl}, 0.27-2.25$ ). These results suggest that selenium is not strongly associated with prostate cancer risk in British men.

British Journal of Cancer (2004) 90, 1392-1396. doi:I0.1038/sj.bjc.660 I70 I www.bjcancer.com

Published online 2 March 2004

(C) 2004 Cancer Research UK

Keywords: selenium; nails; prostate cancer; epidemiology

Selenium is an essential trace element found largely in grains, fish and meat products and has been shown to have antioxidant and other potentially anticarcinogenic properties (Combs and Gray, 1998). Experimental evidence indicates that selenium supplementation can reduce the incidence of viral and chemically induced tumours in animals (Vernie, 1984), including prostate cancer cell lines (Menter et al, 2000).

The selenium content in foods varies widely between regions (Levander, 1987) because it is largely determined by the amount of selenium in the soil. Ecological data suggest that regional cancer mortality rates in the United States are inversely correlated with the selenium concentration in plants (Clark et al, 1991), and a randomised controlled trial among skin cancer patients found selenium supplementation of $200 \mu \mathrm{g} \mathrm{day}^{-1}$ to be associated with a significant $63 \%$ reduction in prostate cancer incidence (Clark et al, 1996; Duffield-Lillico et al, 2002). However, little is known about the relationship between the selenium status and prostate cancer risk in the general population.

The aim of this study is to investigate the association between nail selenium concentration, a marker of long-term intake, and prostate cancer risk. A subsidiary aim is to examine whether factors that may influence selenium status, such as smoking (Hunter et al, 1990), vitamin E intake (Diplock, 1978) or the aggressiveness of disease at the time of recruitment (Yoshizawa et al, 1998; Goodman et al, 2001) modify the association between selenium concentration and prostate cancer risk.

*Correspondence: Dr NE Allen; E-mail: naomi.allen@cancer.org.uk Received 6 November 2003; revised 12 January 2004; accepted 15 January 2004; published online 2 March 2004

\section{SUBJECTS AND METHODS}

A population-based case-control study of the association between diet and prostate cancer was established in Britain, between 1989 and 1992, and included 328 men with incident prostate cancer and 328 population-based controls (Key et al, 1997). The study was restricted to white men under the age of 75 years who could speak English and who were well enough to complete a diet interview and give a reasonable history. Identification of cases was by searching appropriate medical records and cancer registries throughout Oxfordshire, West Berkshire and Leeds; the study was approved by the local ethics committees in these areas. The date of diagnosis was taken as the date on the histopathology report or the date of the first letter from the consultant giving a diagnosis of prostate cancer. Cases were classified as having advanced prostate cancer if there was radiological or histopathological evidence of local invasion and/or metastases to the bone or soft tissue. Controls were taken from the patient list of the general practitioner of each case and were matched on age (within 1 year) and region of residence. Men who had a previous diagnosis of prostate cancer or who had had a radical prostatectomy were not eligible as controls. One control was selected for each case, based either on the closest date of birth (for practices with computerised records) or on alphabetical order of surname after omitting the first 10 patients following the case (for practices without computerised records). Of the 425 eligible cases identified, 328 were interviewed $(77.2 \%), 33$ refused $(7.8 \%)$, for 28 the general practitioner had advised against contact $(6.6 \%), 34$ had died before an interview could be obtained $(8.0 \%)$ and two had emigrated outside the study area $(0.5 \%)$. Of the first 328 controls selected, 267 agreed to be interviewed (81.4\%), 42 refused (12.8\%) and for 19 the consultant or general practitioner had advised against contact (5.8\%). Informed written 
consent was obtained from each of the study subjects. All men were interviewed by one of three female interviewers, who also took fingernail clippings at the same time as completion of the interview. The same interviewer covered all the cases and controls in each of the three health districts. In total, $93 \%$ of cases were interviewed within 1 year of diagnosis (median interval of 4 months).

All participants completed a questionnaire that included details of age, anthropometric, smoking and other lifestyle factors as well as a detailed semiquantitative food-frequency questionnaire that assessed intake of 83 food items during the last 5 years. Study participants were invited to contribute fingernail clippings, of which $632(96 \%)$ did so. Nail clippings were kept in an envelope marked with a unique study identification number and stored at room temperature until analysis. The selenium content was assayed using instrumental neutron activation analysis techniques at the University of Missouri-Columbia Research Reactor Center, Columbia, USA. Case and control specimens were analysed within the same batch in random order and laboratory personnel were blinded to the case-control status of each individual. Nail clippings were thoroughly washed with de-ionised water and freeze-dried. Specimens were irradiated with neutrons and transferred to a high-resolution gamma-ray spectrometer where the gamma-ray from the decay of ${ }^{77 m}$ Se was quantified and selenium concentrations were determined by standard comparison. For 94 subjects, there was adequate sample to prepare and analyse at least two replicate subsamples to check sample homogeneity and analytical reproducibility. A mean and standard deviation was calculated for each replicate. The average relative standard deviation of the mean for these 94 replicate sets was $4.1 \%$. A Standard Reference Material, supplied by the National Institutes of Standards and Technology (NIST SRM 1577 Bovine Liver) having a certified selenium concentration ( $1.1 \pm 0.1$ p.p.m.) was analysed with each sample batch. In total, 24 aliquots of NIST SRM 1577 were analysed giving a relative standard deviation of the mean of $3.3 \%$.

\section{Statistical analysis}

Since the distributions of nail selenium values and dietary intakes were skewed toward the higher levels, these values were naturally logarithmically transformed to approximate a normal distribution. The means and their corresponding 95 percent confidence intervals $(95 \% \mathrm{CI})$ are presented as back-transformed values. Comparisons of the geometric mean nail selenium concentration by sociodemographic and lifestyle variables were examined using analysis of variance. Comparison of the mean selenium concentration by case-control status was examined using the paired $t$ test and analysis of variance, where appropriate. Selenium values were categorised into fourths based on the distribution among the control subjects and the association between nutrient intake and selenium concentration was assessed using one-way analysis of variance. Relative risks were estimated as odds ratios (with their corresponding 95\% CIs) using conditional logistic regression techniques and potential confounders were included as covariates in the models. Odds ratios for each quartile were calculated using the lowest fourth as the referent category. Where appropriate, a test for linear trend was performed to assess statistical significance across exposure categories by including the median value of each quartile among the controls as a continuous variable in the models. All $P$-values were based on two-tailed tests and a value of less than 0.05 was considered statistically significant. Interaction effects were examined between the selenium status and the aggressiveness of the disease, smoking and vitamin $\mathrm{E}$ intake. For the latter analysis, selenium concentration and vitamin $\mathrm{E}$ intake were categorised into two groups according to the median concentration among the controls. Interaction effects were assessed by the likelihood ratio test for the interaction term added to a model that also included the variables as separate factors. All analyses were conducted using Stata version 8.0 (Statacorp, 2003).

\section{RESULTS}

Out of the 656 study participants, 24 subjects did not provide nail samples (17 cases; seven controls) and five subjects had selenium values that remained very high after repeated laboratory analysis (range 4.6-35.1 p.p.m.) and were thus excluded from subsequent statistical analysis (one case; four controls). In total, 300 casecontrol pairs were available for analysis.

The mean age at the time of recruitment was 68.6 for cases and 68.3 for controls and ranged from 44 to 77 years. Among the 300 controls, selenium values ranged six-fold from 0.354 to 2.102 p.p.m. with a median concentration of 0.593 p.p.m. and an interquartile range of $0.498-0.705$ p.p.m. Table 1 shows the geometric mean selenium concentration according to baseline characteristics among the 300 control subjects. The mean nail selenium concentration differed significantly by region, being highest in men recruited from Oxfordshire and lowest in men recruited from the Leeds region (test for heterogeneity; $P<0.0001$ ). However, adjustment for age group, smoking status and total energy intake reduced the differences in nail selenium concentration among the three regions $(P=0.06$; results not shown). Smoking was significantly associated with nail selenium concentration, with current smokers having, on average, a 14\% lower selenium concentration than never smokers and a $10 \%$ lower concentration than past smokers (test for heterogeneity:

Table I Geometric mean selenium concentration according to baseline characteristics among 300 controls

\begin{tabular}{|c|c|c|c|}
\hline Variable & Number & $\begin{array}{c}\text { Mean Se } \\
\text { concentration }\end{array}$ & $P$-value \\
\hline \multicolumn{4}{|l|}{ Age (years) } \\
\hline$<60$ & 17 & 0.690 & \\
\hline $60-69$ & 124 & 0.600 & \\
\hline $70+$ & 159 & 0.612 & 0.15 \\
\hline \multicolumn{4}{|l|}{ Region } \\
\hline Oxfordshire & 102 & 0.643 & \\
\hline West Berkshire & 109 & 0.614 & \\
\hline Leeds & 89 & 0.573 & $<0.000$ । \\
\hline \multicolumn{4}{|c|}{$\mathrm{BMl}$ at age 25 years $\left(\mathrm{kg} \mathrm{m}^{-2}\right)^{\mathrm{a}}$} \\
\hline$<21.3$ & 112 & 0.606 & \\
\hline $21.3-23.3$ & 91 & 0.625 & \\
\hline $23.4+$ & 96 & 0.601 & 0.63 \\
\hline \multicolumn{4}{|c|}{$\mathrm{BMl}$ at age 45 years $\left(\mathrm{kg} \mathrm{m}^{-2}\right)^{\mathrm{b}}$} \\
\hline$<23.0$ & 110 & 0.604 & \\
\hline $23.0-25.3$ & 97 & 0.626 & \\
\hline $25.4+$ & 91 & 0.603 & 0.60 \\
\hline \multicolumn{4}{|l|}{ Smoking } \\
\hline Never & 74 & 0.643 & \\
\hline Past & 175 & 0.615 & \\
\hline Current & 51 & 0.556 & 0.01 \\
\hline \multicolumn{4}{|l|}{ Cigarettes day $^{-/ c}$} \\
\hline$<20$ & 24 & 0.599 & \\
\hline $20+$ & 27 & 0.520 & 0.06 \\
\hline \multicolumn{4}{|l|}{ Social class } \\
\hline I, II, III nonmanual & 167 & 0.624 & \\
\hline III manual, IV, V & 133 & 0.595 & 0.15 \\
\hline
\end{tabular}


$P=0.014)$. Among current smokers, men who smoked 20 cigarettes or more per day had $13 \%$ lower levels than men who smoked less than 20 cigarettes per day, although this difference was not statistically significant $(P=0.06)$. Age, body mass index $\left(\mathrm{BMI}\right.$; weight $\left.(\mathrm{kg}) / \mathrm{height}(\mathrm{m})^{2}\right)$ at ages 25 and 45 years and social class were not associated with nail selenium concentration.

Table 2 shows the association of baseline characteristics with cancer risk among 300 prostate cancer cases and their controls. Social class was significantly associated with prostate cancer risk; men in the lower social class group had a $54 \%$ increased risk of developing prostate cancer compared with men in a higher social class group (OR 1.54; 95\% CI, 1.09-2.18). The proportion of men with a family history of prostate cancer was higher among cases than controls, although the association was not statistically significant (OR 2.14; 95\% CI, 0.87-5.26). Marital status, smoking and BMI at age 25 or 45 years were not associated with risk. These associations are similar to those previously reported in the full case-control study of 656 subjects (Key et al, 1997).

There was no significant difference in the mean selenium concentration between cases and controls; the geometric mean was 0.622 p.p.m. in cases and 0.611 p.p.m. in controls $(P=0.454$, Table 3); adjustment for social class made no appreciable difference to the means (results not shown). There was also no significant difference between the geometric mean selenium concentration in men with localised or advanced cancer and that of their controls (Table 3), or between men with localised and advanced disease $(P=0.215)$.

Table 2 Association between baseline characteristics and prostate cancer risk

\begin{tabular}{|c|c|c|c|}
\hline & $\begin{array}{c}\text { Cases } \\
(n=300)\end{array}$ & $\begin{array}{l}\text { Controls } \\
(n=300)\end{array}$ & $\begin{array}{c}\text { Odds ratio } \\
(95 \% \mathrm{Cl})\end{array}$ \\
\hline \multicolumn{4}{|l|}{ Marital status ${ }^{\mathrm{a}}$} \\
\hline Married & 228 & 245 & 1.00 \\
\hline Unmarried & 72 & 55 & $1.40(0.95-2.09)$ \\
\hline Test for heterogeneity & & & $P=0.11$ \\
\hline \multicolumn{4}{|l|}{ Smoking status } \\
\hline Never & 75 & 74 & 1.00 \\
\hline Past & 175 & 175 & $0.99(0.66-1.47)$ \\
\hline Current & 50 & 51 & $0.97(0.59-1.59)$ \\
\hline Test for heterogeneity & & & $P=0.90$ \\
\hline \multicolumn{4}{|c|}{ Family history of prostate cancer ${ }^{b}$} \\
\hline No & 285 & 293 & 1.00 \\
\hline Yes & 15 & 7 & $2.14(0.87-5.26)$ \\
\hline Test for heterogeneity & & & $P=0.10$ \\
\hline \multicolumn{4}{|l|}{ Social class } \\
\hline I,II,III nonmanual & 139 & 167 & 1.00 \\
\hline III manual, IV, V & 161 & 133 & $1.54(1.09-2.18)$ \\
\hline Test for heterogeneity & & & $P=0.02$ \\
\hline \multicolumn{4}{|c|}{ BMl at age 25 years $\left(\mathrm{kg} \mathrm{m}^{-2}\right)$} \\
\hline$<21.3$ & 94 & 112 & 1.00 \\
\hline $21.3-23.3$ & 113 & 91 & $1.45(0.98-2.15)$ \\
\hline $23.4+$ & 91 & 96 & $1.14(0.77-1.69)$ \\
\hline Test for linear trend & & & $P=0.53$ \\
\hline \multicolumn{4}{|c|}{ BMl at age 45 years $\left(\mathrm{kg} \mathrm{m}^{-2}\right)$} \\
\hline$<23.0$ & 91 & 110 & 1.00 \\
\hline $23.0-25.3$ & 97 & 97 & $1.19(0.80-1.73)$ \\
\hline $25.4+$ & 110 & 91 & $1.42(0.97-2.08)$ \\
\hline Test for linear trend & & & $P=0.07$ \\
\hline
\end{tabular}

Details of risk by quartile of nail selenium concentration are shown in Table 4: overall, no association was found, either before or after adjustment for social class. Men in the highest quartile had a nonsignificant increased risk compared with men in the lowest quartile (OR 1.24; 95\% CI, 0.73-2.10). Additional adjustment for smoking made no difference to the association between selenium concentration and risk and the association was similar when current smokers were excluded from the analysis (results not shown). The test for multiplicative interaction between selenium concentration (in quartiles) and smoking status was not statistically significant after including these terms together with the interaction term into the model $(P=0.169)$. Additional adjustment for food items and nutrients found to be associated with prostate cancer risk in our study of a previous analysis of this study population, including garlic, beans, peas and vitamin $\mathrm{B}_{6}$ intake (Key et al, 1997) made no appreciable difference to the risk estimates and were not included in the final model.

Selenium concentration was not associated with localised or advanced disease (Table 4). However, men in the highest quartile of selenium nail concentration had a non-significant $22 \%$ reduced risk of developing advanced prostate cancer compared with men in the lowest selenium quartile $(\mathrm{OR}=0.78 ; 95 \% \mathrm{CI}, 0.27-2.25)$.

There was no evidence that vitamin $\mathrm{E}$ intake was independently associated with risk, either before or after adjustment for social class (OR for vitamin E intake of 12 or more mg day ${ }^{-1} v s$ less than $\left.12 \mathrm{mg} \mathrm{day}^{-1}=0.85 ; 95 \% \mathrm{CI}, 0.62-1.17\right)$, and there was no evidence of interaction with selenium concentration on risk $(P=0.729)$.

\section{DISCUSSION}

The findings from this study suggest that selenium concentration, as measured in fingernail clippings, is not strongly associated with prostate cancer risk. Although previous studies have assessed the selenium content in toe nails, which is $9-15 \%$ lower than that of fingernails (Baskett et al, 1995), selenium concentrations in these British men are still somewhat lower than those reported in North American populations (Yoshizawa et al, 1998; Ghadirian et al, 2000; Helzlsouer et al, 2000) and are comparable with other European populations (Kardinaal et al, 1997; van den Brandt et al, 2003). It is well established that the selenium content of European soils is low and that dietary intake has been gradually declining due to a reduction in imported selenium-rich wheat from the US and Canada, together with a general decline in cereal consumption (Rayman, 1997). Indeed, it is estimated that selenium intake in the UK has declined by about a third from an average of $60 \mu \mathrm{g} \mathrm{day}^{-1}$ in the late $1970 \mathrm{~s}$ to $30-40 \mu \mathrm{g} \mathrm{day}^{-1}$ in the late $1990 \mathrm{~s}$, which is approximately half the reference daily intake of $75 \mu \mathrm{g} \mathrm{day}^{-1}$ for adult men (Rayman, 1997). Although dietary selenium intake was not estimated in this study population because of the wide variation in soil selenium content and the lack of information about supplemental selenium use, the low nail selenium concentrations confirm that dietary intake in British men is indeed lower than that of typical North American populations.

Our finding that current smokers have lower selenium levels than never-smokers is consistent with previous studies

Table 3 Geometric mean nail selenium concentrations in cases and controls

\begin{tabular}{ccccccc}
\hline & \multicolumn{2}{c}{ Cases } & & \multicolumn{2}{c}{ Controls } & \\
\cline { 2 - 3 } & Number & Mean & & Number & Mean & P-value \\
\hline Total cancer & 300 & 0.622 & & 300 & 0.611 & 0.45 \\
Localised & 211 & 0.631 & & 211 & 0.607 & 0.17 \\
Advanced & 89 & 0.602 & & 89 & 0.621 & 0.47 \\
\hline
\end{tabular}


Table 4 Association of nail selenium concentration with prostate cancer risk ${ }^{\mathrm{a}}$

\begin{tabular}{|c|c|c|c|c|c|c|c|}
\hline $\begin{array}{l}\begin{array}{l}\text { Quartile of nail } \\
\text { selenium }\end{array} \\
<0.497\end{array}$ & $\begin{array}{c}\begin{array}{c}\text { Quartile } \\
\text { median } \\
\text { (p.p.m.) }\end{array} \\
0.456\end{array}$ & \multicolumn{2}{|c|}{ Total prostate cancer ( $n=300$ cases) } & \multicolumn{2}{|c|}{ Localised cancer ( $n=211$ cases) } & \multicolumn{2}{|c|}{ Advanced cancer ( $n=89$ cases) } \\
\hline $0.497-0.592$ & 0.547 & 84 & $1.39(0.87-2.23)$ & 61 & $1.54(0.85-2.77)$ & 23 & $0.99(0.43-2.26)$ \\
\hline $0.593-0.704$ & 0.635 & 80 & $1.25(0.78-2.02)$ & 57 & $1.59(0.90-2.82)$ & 23 & $0.65(0.26-1.56)$ \\
\hline $\begin{array}{l}0.705+ \\
\text { Test for linear } \\
\text { trend }\end{array}$ & 0.837 & 74 & $\begin{array}{c}1.24(0.73-2.10) \\
P=0.581\end{array}$ & 54 & $\begin{array}{c}1.45(0.78-2.70) \\
P=0.313\end{array}$ & 20 & $\begin{array}{c}0.78(0.27-2.25) \\
P=0.480\end{array}$ \\
\hline
\end{tabular}

${ }^{a}$ All results are matched for age and region and adjusted for social class.

(Hunter et al, 1990; Swanson et al, 1990; van den Brandt et al, 1993). However, smoking was not associated with risk in this study population and additional adjustment for smoking made no appreciable difference to the association between selenium concentration and cancer risk.

The hypothesis that selenium and vitamin $\mathrm{E}$ intake may interact to influence prostate cancer risk has been largely derived from animal studies (Diplock, 1978) and from a randomised controlled trial that found $\alpha$-tocopherol to be associated with a reduced risk of prostate cancer (Heinonen et al, 1998). Indeed, a trial specifically designed to test the joint efficacy of selenium and vitamin $\mathrm{E}$ for the prevention of prostate cancer is underway (Klein et al, 2003). Evidence from observational studies has, however, been inconsistent; although one study found that risk was lowest among men with both a high selenium and $\delta$-tocopherol level (Helzlsouer et al, 2000), the present study and others have found no interaction of vitamin $\mathrm{E}$ intake and selenium levels with risk (Hartman et al, 1998; Yoshizawa et al, 1998; Vogt et al, 2003).

The main strengths of this study are the large number of cases and controls, the ability to categorise cancers into localised and advanced disease, and detailed information on potential confounding factors. Further, selenium measures based on nail samples have been shown to reflect selenium intake integrated over the previous 6-12 months (Morris et al, 1983) and can be used to rank subjects according to long-term dietary selenium intake (Longnecker et al, 1996). Moreover, a single measure has shown moderate reliability over a 6-year period, with a correlation coefficient of 0.48 (Garland et al, 1993).

The main limitation of this study is the possibility that the cancer or its treatment may affect nutritional status and thereby selenium levels. However, as nails reflect nutritional status for up to a year prior to clipping, any recent changes in nutrient intake or physiology are unlikely to influence nail concentration over the short-term. The observation that the mean selenium concentration was similar between men with localised and advanced disease also suggests that disease status is unlikely to influence the association between selenium concentration and prostate cancer risk in this study population.

In conclusion, the findings from this study suggest that selenium concentration, as measured in nail clippings, is not strongly associated with prostate cancer risk in British men. This is in contrast to the results of the Nutritional Prevention of Cancer trial that found selenium supplementation to be associated with a significant reduction in prostate cancer risk (Clark et al, 1996; Duffield-Lillico et al, 2002). Several prospective studies have also found significant protective associations for serum or nail selenium levels in relation to prostate cancer (Yoshizawa et al, 1998; Helzlsouer et al, 2000; Nomura et al, 2000; Brooks et al, 2001; van den Brandt et al, 2003). However, consistent with the findings from the present study, some other observational studies have failed to find such an association (Willett et al, 1983; Coates et al, 1988; Knekt et al, 1990; Hardell et al, 1995; Ghadirian et al, 2000; Goodman et al, 2001; Vogt et al, 2003). It is unclear whether these epidemiological data overall are or are not supportive of a reduction in prostate cancer risk with high selenium intake, and a pooled analysis might be informative.

\section{ACKNOWLEDGEMENTS}

We thank all the participants of the study, Rosemary Brett, Elizabeth Hilton and Bette Ward for identifying and interviewing the study participants; and the urologists, general practitioners, radiologists, pathologists, cancer registry staff and other medical staff who helped in identifying and contacting study participants. This study was set up by funding from Cancer Research UK; funding for this analysis was supported by a grant from the US Department of Defence (DAMD-17-12-1-0071).

\section{REFERENCES}

Baskett CK, Spate VL, Morris JS, Anderson HD, Mason MM, Reams CL, Cheng TP, Zinn KR, Hill GR, Dowdy RP (1995) Investigation of the appearance of supplemental enriched Se-76 using the human nail as a dietary monitor. J Radioanal Nucl Chem Articles 195: 97-108

Brooks JD, Metter EJ, Chan DW, Sokoll LJ, Landis P, Nelson WG, Muller D, Andres R, Carter HB (2001) Plasma selenium level before diagnosis and the risk of prostate cancer development. J Urol 166: 2034-2038

Clark LC, Cantor KP, Allaway WH (1991) Selenium in forage crops and cancer mortality in U.S. counties. Arch Environ Health 46: 37-42

Clark LC, Combs GFJ, Turnbull BW, Slate EH, Chalker DK, Chow J, Davis LS, Glover RA, Graham GF, Gross EG, Krongrad A, Lesher JLJ, Park HK, Sanders BBJ, Smith CL, Taylor JR (1996) Effects of selenium supplementation for cancer prevention in patients with carcinoma of the skin. A randomized controlled trial. Nutritional Prevention of Cancer Study Group. JAMA 276: 1957-1963

Coates RJ, Weiss NS, Daling JR, Morris JS, Labbe RF (1988) Serum levels of selenium and retinol and the subsequent risk of cancer. Am J Epidemiol 128: $515-523$

Combs GFJ, Gray WP (1998) Chemopreventive agents: selenium. Pharmacol Ther 79: 179-192

Diplock AT (1978) The biological function of vitamin E and the nature of the interaction of the vitamin with selenium. World Rev Nutr Diet 31: $178-183$

Duffield-Lillico AJ, Reid ME, Turnbull BW, Combs GFJ, Slate EH, Fischbach LA, Marshall JR, Clark LC (2002) Baseline characteristics and the effect of selenium supplementation on cancer incidence in a randomized clinical 
trial: a summary report of the Nutritional Prevention of Cancer Trial. Cancer Epidemiol Biomark Prev 11: 630-639

Garland M, Morris JS, Rosner BA, Stampfer MJ, Spate VL, Baskett CJ, Willett WC, Hunter DJ (1993) Toenail trace element levels as biomarkers: reproducibility over a 6-year period. Cancer Epidemiol Biomark Prev 2: $493-497$

Ghadirian P, Maisonneuve P, Perret C, Kennedy G, Boyle P, Krewski D, Lacroix A (2000) A case-control study of toe-nail selenium and cancer of the breast, colon, and prostate. Cancer Detect Prev 24: 305-313

Goodman GE, Schaffer S, Bankson DD, Hughes MP, Omenn GS (2001) Predictors of serum selenium in cigarette smokers and the lack of association with lung and prostate cancer risk. Cancer Epidemiol Biomark Prev 10: 1069-1076

Hardell L, Degerman A, Tomic R, Marklund SL, Bergfors M (1995) Levels of selenium in plasma and glutathione peroxidase in erythrocytes in patients with prostate cancer or benign hyperplasia. Eur J Cancer Prev 4: $91-95$

Hartman TJ, Albanes D, Pietinen P, Hartman AM, Rautalahti M, Tangrea JA, Taylor PR (1998) The association between baseline vitamin E, selenium, and prostate cancer in the alpha-tocopherol, beta-carotene cancer prevention study. Cancer Epidemiol Biomark Prev 7: 335-340

Heinonen OP, Albanes D, Virtamo J, Taylor PR, Huttunen JK, Hartman AM, Haapakoski J, Malila N, Rautalahti M, Ripatti S, Maenpaa H, Teerenhovi L, Koss L, Virolainen M, Edwards BK (1998) Prostate cancer and supplementation with alpha-tocopherol and beta-carotene: incidence and mortality in a controlled trial. J Natl Cancer Inst 90: 440 - 446

Helzlsouer KJ, Huang HY, Alberg AJ, Hoffman S, Morris SJ, Comstock GW (2000) Association between alpha-tocopherol, gamma-tocopherol, selenium and subsequent prostate cancer. J Natl Cancer Inst 92: 2018-2023

Hunter DJ, Morris JS, Chute CG, Kushner E, Colditz GA, Stampfer MJ, Speizer FE, Willett WC (1990) Predictors of selenium concentration in human toenails. Am J Epidemiol 132: 114-122

Kardinaal AF, Kok FJ, Kohlmeier L, Martin-Moreno JM, Ringstad J, GomezAracena J, Mazaev VP, Thamm M, Martin BC, Aro A, Kark JD, DelgadoRodriguez M, Riemersma RA, van't Veer P, Huttunen JK (1997) Association between toenail selenium and risk of acute myocardial infarction in European men: the EURAMIC Study. Am J Epidemiol 145: $373-379$

Key TJ, Silcocks PB, Davey GK, Appleby PN, Bishop DT (1997) A case-control study of diet and prostate cancer. Br J Cancer 76: 678-687

Klein EA, Lippman SM, Thompson IM, Goodman PJ, Albanes D, Taylor PR, Coltman C (2003) The selenium and vitamin E cancer prevention trial. World J Urol 21: 21-27
Knekt P, Aromaa A, Maatela J, Alfthan G, Aaran RK, Hakama M, Hakulinen T, Peto R, Teppo L (1990) Serum selenium and subsequent risk of cancer among Finnish men and women. J Natl Cancer Inst 82: 864-868

Levander OA (1987) A global view of human selenium nutrition. Annu Rev Nutr 7: $227-250$

Longnecker MP, Stram DO, Taylor PR, Levander OA, Howe M, Veillon C, McAdam PA, Patterson KY, Holden JM, Morris JS, Swanson CA, Willet WC (1996) Use of selenium concentration in whole blood, serum, toenails, or urine as a surrogate measure of selenium intake. Epidemiology 7: 384-390

Menter DG, Sabichi AL, Lippman SM (2000) Selenium effects on prostate cell growth. Cancer Epidemiol Biomark Prev 9: 1171-1182

Morris JS, Stampfer MJ, Willett WC (1983) Dietary selenium in humans: toenails as an indicator. Biol Trace Elem Res 5: 529-537

Nomura AM, Lee J, Stemmermann G, Combs GFJ (2000) Serum selenium and subsequent risk of prostate cancer. Cancer Epidemiol Biomark Prev 9: $883-887$

Rayman MP (1997) Dietary selenium: time to act. BMJ 314: $387-388$

Statacorp (2003) Stata Statistical Software, Release 8.0. College Station, TX: Stata Corporation

Swanson CA, Longnecker MP, Veillon C, Howe M, Levander OA, Taylor PR, McAdam PA, Brown CC, Stampfer MJ, Willett WC (1990) Selenium intake, age, gender, and smoking in relation to indices of selenium status of adults residing in a seleniferous area. Am J Clin Nutr 52: 858-862

van den Brandt PA, Goldbohm RA, van't Veer P, Bode P, Hermus RJ Sturmans F (1993) Predictors of toenail selenium levels in men and women. Cancer Epidemiol Biomark Prev 2: 107-112

van den Brandt PA, Zeegers MP, Bode P, Goldbohm RA (2003) Toenail selenium levels and the subsequent risk of prostate cancer: a prospective cohort study. Cancer Epidemiol Biomark Prev 12: 866-871

Vernie LN (1984) Selenium in carcinogenesis. Biochim Biophys Acta 738: $203-217$

Vogt TM, Ziegler RG, Graubard BI, Swanson CA, Greenberg RS, Schoenberg JB, Swanson GM, Hayes RB, Mayne ST (2003) Serum selenium and risk of prostate cancer in US blacks and whites. Int $J$ Cancer 103: $664-670$

Willett WC, Polk BF, Morris JS, Stampfer MJ, Pressel S, Rosner B, Taylor JO, Schneider K, Hames CG (1983) Prediagnostic serum selenium and risk of cancer. Lancet 2: 130-134

Yoshizawa K, Willett WC, Morris SJ, Stampfer MJ, Spiegelman D, Rimm EB, Giovannucci E (1998) Study of prediagnostic selenium level in toenails and the risk of advanced prostate cancer. J Natl Cancer Inst 90: $1219-1224$ 